\title{
Ramp meters on trial: Evidence from the Twin Cities metering holiday
}

\author{
David Levinson $^{\text {a,* }}$, Lei Zhang ${ }^{\text {b,1 }}$ \\ ${ }^{a}$ Department of Civil Engineering, University of Minnesota, 500 Pillsbury Drive SE, Minneapolis, MN 55455, United States \\ b Department of Civil, Construction, and Environmental Engineering, Oregon State University, 220 Owen Hall, Corvallis, OR 97331, USA
}

Received in revised form 4 October 2004; accepted 15 December 2004

\begin{abstract}
Ramp meters in the Twin Cities have been the subject of a recent test of their effectiveness, involving turning them off for eight weeks. This paper analyzes the results with and without ramp metering for several representative freeways during the afternoon peak period. Seven performance measures: mobility, equity, productivity, consumers' surplus, accessibility, travel time variation and travel demand responses are compared. It is found that ramp meters are particularly helpful for long trips relative to short trips. Ramp metering, while generally beneficial to freeway segments, may not improve trip travel times (including ramp delays). The reduction in travel time variation comprises another benefit from ramp meters. Non-work trips and work trips respond differently to ramp meters. The results are mixed, suggesting a more refined ramp control algorithm, which explicitly considers ramp delay, is in order.
\end{abstract}

(c) 2006 Elsevier Ltd. All rights reserved.

Keywords: Ramp meters; Evaluation; Equity; Mobility; Accessibility; Productivity; Consumers' surplus; Travel time variation; Travel demand

\section{Introduction}

Ramp meters in the Twin Cities of Minneapolis and St. Paul, Minnesota have been the subject of a recent test of their effectiveness. Using data from their shutdown for eight weeks in October, November, and December 2000, it has been possible to determine how well the meters meet stated objectives, and to provide new insight into the appropriateness of those objectives. Ramp meters in the Twin Cities were intended "to optimize flow in metro area freeway corridors by making efficient use of available transportation facilities" (Minnesota Department of Transportation (MnDOT), 1996). This paper presents the detailed results of an analysis of observed data of several representative freeways, Trunk Highway (TH) 169 northbound and southbound, I-494 outer-loop/inner-loop and TH62 westbound during the afternoon peak period, and considers a variety

\footnotetext{
* Corresponding author. Tel.: +1 612625 6354; fax: +1 6126267750 .

E-mail addresses: levin031@tc.umn.edu (D. Levinson), lei.zhang@oregonstate.edu (L. Zhang).

${ }^{1}$ Tel.: 541737 2072; fax: 5417373052.
} 
of measures of effectiveness with and without ramp meters. This research identifies a number of alternative performance measures, including mobility, equity, productivity, consumers' surplus, accessibility, travel time variation, and changes in travel demand, to assess the effectiveness of metering.

Ramp metering was first implemented in 1963 on the Eisenhower Expressway (I-290) in Chicago (MnDOT, 2002). This first application involved a police officer who would stop traffic on an entrance ramp and release vehicles one at a time at a predetermined rate, so that the objectives of safer and smoother merging onto the freeway traffic was easier without disrupting the mainline flows. Since then ramp-meters have been systematically deployed in many US metropolitan areas including Phoenix, AZ; Los Angeles, CA; Fresno, CA; Sacramento, CA; San Francisco, CA; San Diego, CA; Denver, CO; Atlanta, GA; Chicago, IL; Detroit, MI; Twin Cities, MN; Las Vegas, NV; Long Island, NY; New York, NY; Cleveland, OH; Lehigh Valley area, PA; Philadelphia, PA; Houston, TX; Arlington, VA; Milwaukee, WI; and Seattle, WA; as well as in cities in other countries including Sydney, Australia; Toronto, Canada; and Birmingham and Southampton, UK. Ramp meters have been withdrawn after initial introduction in several US cities, including Austin, TX; Dallas, TX; San Antonio, TX; and Columbus, OH.

The Minnesota Department of Transportation first installed meters in 1969 on entrance ramps to I-35E at Maryland Avenue and Wheelock Parkway in St. Paul. Additional ramps were brought into service on the same freeway (MnDOT, 2002). Observed improvements in traffic flow, higher speeds and fewer accidents led to more ramp-meters in 1971. In Minneapolis, metering began on I-35W through south Minneapolis in 1970, followed by meters near the Lowry Hill tunnel on I-94. In 1972, MnDOT built a Traffic Management Center (TMC) in downtown Minneapolis to house the equipment and staff necessary for expanded metering. With time, metering was added on nearly every entrance to the I-494/I-694 beltway, except on the metro area's east side, and on most highways inside the I-494/I-694 ring. Fig. 1 shows Twin Cities ramp meter installations from inception. We can clearly see that there have been sharp increases in their numbers in some years. In the 1990s MnDOT adopted a policy favoring metering over capacity expansion in the Twin Cities area, primarily on a cost-effectiveness basis, as well as the belief that meters were easier to implement politically than new roads. By 2000, there were over 443 meters, mostly controlled in real-time by the TMC. Also, initially there were single lane ramp meters, but to avoid spillback onto arterial or connecting roads, the usual practice now is to have two-lane ramp meters.

Ramp meters began to assume an increasingly important role in the freeway management of the Twin Cities. Since 1970, MnDOT has spent nearly $\$ 4$ million to install and upgrade ramp meters, television surveillance and other traffic management measures (MnDOT, 2002). Initially, meter installation did not draw political

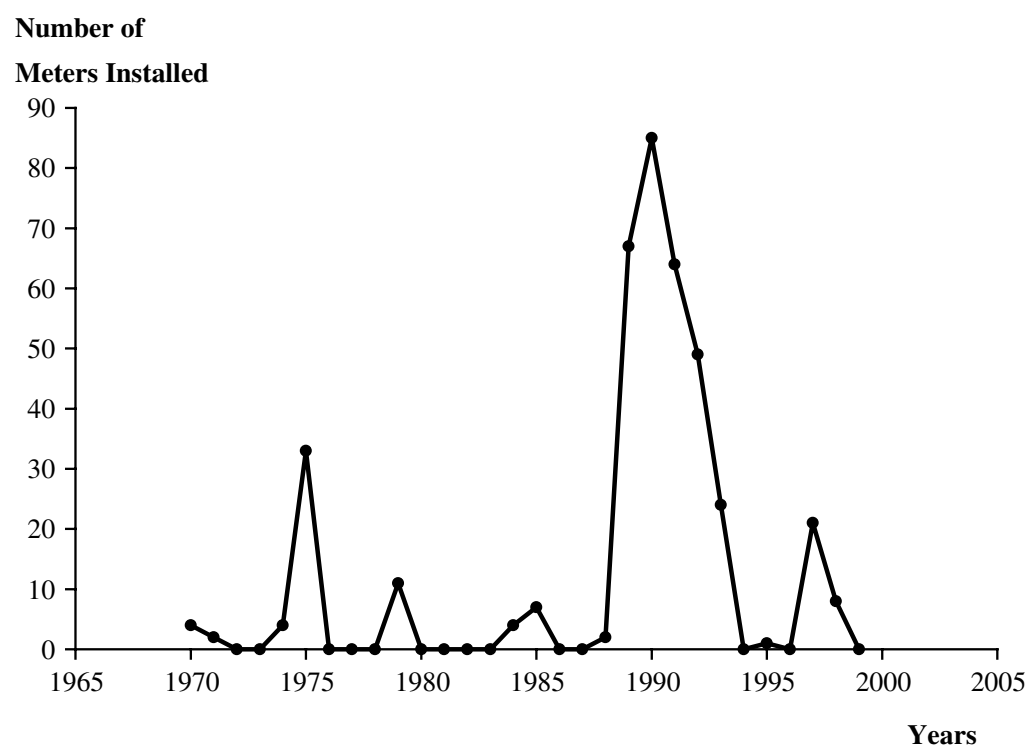

Fig. 1. Ramp meter installation timeline in the Twin Cities. 
attention or spark public policy debates because it was seen to have helped smooth congestion without major inconvenience to drivers. Only in recent years, with congestion increasing and meter waits stretching beyond the level of driver acceptability (some waits in excess of $20 \mathrm{~min}$ ), have drivers and legislators begun to question the meters' value, believing at best that the system was inefficiently managed by MnDOT.

The most vocal of metering opponents was Minnesota's Senate Republican leader Dick Day (Owatonna), who argued that the ramp meters cause both congestion and driver frustration. Early in 1999, Senator Day proposed turning off the ramp meters for a temporary period to test their effectiveness. In October 1999, he put forward his "Freedom to Drive" plan which promised to ease metro area congestion by turning off the ramp meters, raising speed limits, and using the left lane only for passing (Star Tribune, 1999). The proposal was passed in the Senate but failed in the House in the 1999 legislative session. Senator Day argued that MnDOT had been withholding information from the public about the real effectiveness of ramp meters and had exaggerated the advantages of metering in order to continue funding metering projects while ignoring frustrated commuters waiting on the ramps. He linked his passion for turning off ramp meters to Americans' love for their cars, of being independent and driving unaffected by 'unnecessary' waits on the ramps. MnDOT's support of delay-inducing metering was linked to support for new rail transit lines (the financial support of the Hiawatha Light Rail line connecting downtown Minneapolis with the Airport and Mall of America was an active question at the same time - it has since passed).

The Transportation Finance Bill passed both houses of the state legislature in May 2000, increasing spending on roads and bridges, and including a provision for a month long "Ramp meter holiday" slated to take place in October 2000. MnDOT extended the study to two months. The bill required a study of the effectiveness of ramp meters in the Twin Cities metro area by conducting a shutdown study before the next legislative session.

The national consultancy Cambridge Systematics was selected to conduct the legislature's authorized study of ramp metering (Cambridge Systematics, 2001). A set of three studies of ramp meters by researchers at the University of Minnesota (including this one) were already approved when the shutdown was mandated by the legislature (Hourdakis and Michalopoulos, 2002; Kwon et al., 2001).

This paper analyzes the data collected with and without metering. The next section outlines the various performance measures and shows how they are computed. The following section details the method used to measure travel times at on-ramps and freeway mainline segments from the data available. The Minnesota Algorithm is described. Then the data used in this study is introduced, followed by the results on studied freeways for each of the performance measures. Recommendations and conclusions are delivered at the end of this paper.

\section{Performance measures}

The evaluation of transportation systems garners significant attention in the planning, engineering, policy, management, and economics literatures, each of which approaches the problem differently, with unique concerns and objectives (Levinson, 2002a,b). Since each field measures something different, it is important to consider each of those measures when evaluating the ramp metering system. If, after considering multiple measures, we draw the same conclusion (e.g. metering is better than no metering), we can be confident of our result. But if we draw different conclusions, there is no clear answer, but rather trade-offs. This paper intentionally outlines a plurality of measures, reflecting the mobility of traffic engineers, the consumers' surplus of economists, the productivity of managers, the accessibility of planners, as well as the equity of policy analysts. We also consider demand changes and reliability, which are emerging issues for all of the fields. Since a previous study (Cambridge Systematics, 2001) has examined safety impacts of ramp metering comprehensively and in general identified increased crash rates during the shut-off experiment, the number of crashes is not analyzed in this study to avoid repetition.

The equity measure is particularly important to understand the differing perceptions of ramp meter effectiveness that led to the trial. Who, when, and where benefited and lost as a result of meters? Just because society gains does not mean everyone does. While system mobility was in the minds of the traffic engineers who designed and administered the system, individual travel times and their reliability were in the minds of each traveler and legislator who used the system. Accessibility has entered the public debate peripherally through 
the question of whether ramp meters cause sprawl - is access enhanced for suburban areas at the expense of the central city and first ring suburbs (Wascoe, 2000). We look at both overall accessibility as well as spatial equity to answer these questions. The question of consumers' surplus matters, though it has not entered the debate, because it is important to consider that some travelers are metered off the roads so that others can travel faster, these changes in demand change overall welfare. Similarly productivity lets us consider whether we are getting more output from the system per unit input, and is particularly important to commercial users of the system.

\subsection{Mobility and equity}

Mobility, or ease of movement can be measured at on-ramps, freeway segments and for the system as a whole. For mobility, elements in two origin-destination (OD) trip mobility matrices (travel time and speed) can be averaged at various levels, which enable us to look at mobility of different groups of freeway users (e.g. drivers who have the same origin and destination; drivers who enter the freeway in the same time interval; all drivers during the peak period).

The Gini coefficient of concentration (Gini, 1936) and the Lorenz Curve (Lorenz, 1905) have been used in economic studies to analyze income inequality. They are applied here to analyze inequalities of travel time and speed. Using ramp delay inequality as an example (Fig. 2 gives the Lorenz Curve for the case of the Valley View Road on-ramp on TH169 northbound during an afternoon peak period), the Lorenz Curve relates the proportion of the population receiving a given proportion of delay. While the bottom $100 \%$ of the population gets $100 \%$ of delay by definition, the luckiest $50 \%$ may only get $30 \%$ of the delay. Then the Gini coefficient corresponding to this Lorenz Curve can be computed, which is a numerical scalar indicating the degree of ramp delay inequality. Numerically, the Gini coefficient is equal to the ratio of $A_{1} /\left(A_{1}+A_{2}\right)$ in the graph. A much easier way to obtain the Gini coefficient for the ramp delays experienced by a group of drivers $\left(d_{1}, d_{2}, \ldots, d_{V}\right)$, without constructing the Lorenz Curve, is to compute the "relative mean difference", i.e., the mean of the delay difference between every possible pair of drivers, divided by the mean delay (Glasser, 1962):

$$
G=\frac{\sum_{v=1}^{V} \sum_{u=1}^{V}\left|d_{v}-d_{u}\right|}{2 V \sum_{v=1}^{V} d_{v}}
$$

where $G$ is the Gini coefficient; $V$ is the total number of drivers; $d_{v}$ is the ramp delay experienced by driver $v$.

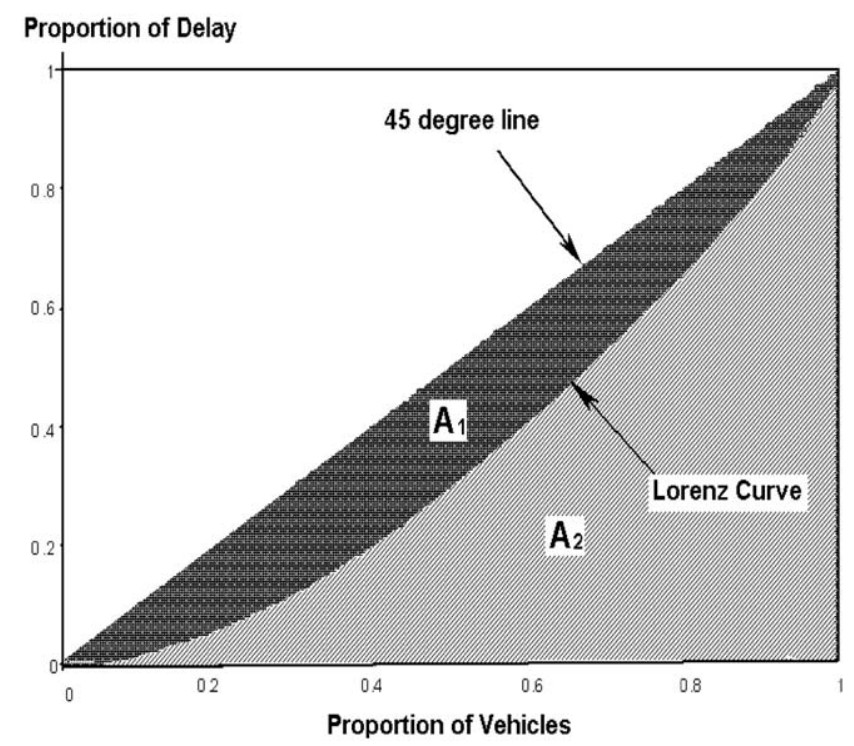

Fig. 2. Lorenz Curve for valley view road on-ramp on TH169. $A_{1}$ is the area between Lorenz Curve and 45-deg line; $A_{2}$ is the rest of triangle defined by Lorenz Curve, $X$-axis, and vertical line projecting from $100 \%$ of the population in question. 
Table 1

Speed OD matrix

\begin{tabular}{|c|c|c|c|c|}
\hline Speed & OD pair 1 & OD pair 2 & $\cdots$ & OD pair $P$ \\
\hline Time interval 1 & Speed 11 & Speed 12 & $\cdots$ & Speed 1P \\
\hline Time interval 2 & Speed 21 & Speed 22 & $\cdots$ & Speed 2P \\
\hline$\cdots$ & $\ldots$ & $\ldots$ & $\ldots$ & $\ldots$ \\
\hline Time interval $K$ & Speed K1 & Speed K2 & $\ldots$ & Speed KP \\
\hline
\end{tabular}

A Gini coefficient of 0 indicates perfect equality, and 1 indicates perfect inequality (one driver suffers all the delay).

For each OD trip mobility matrix, spatial equity, temporal equity, and spatial-temporal equity are evaluated. The computation of these three equity measures and corresponding mobility measures is illustrated using an OD trip speed matrix (see Table 1). If a Gini coefficient is calculated using speeds in all time intervals for a specific OD pair (e.g. speed 11, speed $21, \ldots$, speed $K 1$ for OD pair 1), this Gini coefficient reflects temporal equity of this specific OD pair and is a temporal equity measure. Similarly, the average of these speeds is a temporal mobility measure. Temporal Gini coefficients measure the equity among drivers whose trips have the same origin and destination but start at the origin (an entrance ramp) in different time intervals. On the other hand, if a Gini coefficient is computed using speeds of trips that start in the same time interval but with different OD pairs (e.g. speed 11 , speed $12, \ldots$, speed $1 P$ ), this Gini coefficient evaluates spatial equity in this time interval and thus is a spatial equity measure. The average of these speeds is a spatial mobility measure. Finally, to evaluate the equity and mobility of the whole freeway network throughout a peak period, the spatial-temporal equity and mobility measures can be used respectively, which are calculated by all the $m \times n$ speed values. However, the measure of equity is limited to travel time in this study and does not take into account the socioeconomic characteristics of the population.

\subsection{Consumers' surplus}

Consumer surplus measures the difference between the price of a particular good and the reservation price the buyer is willing to pay for that good. Because the willingness to pay varies between individuals, the consumer surplus also varies. However, consumer surplus can be aggregated across individuals to get consumers' surplus. In general, change in consumers' surplus is used rather than absolute consumers' surplus, because it can be more readily measured. In travel, the price is the travel time while the quantity of the good is the number of vehicles using the road network. As the travel time across a certain stretch of the traffic network decreases, there will be more vehicles willing to access the same stretch pushing the flow up. Mathematically, this aggregate change in consumers' surplus $(\triangle \mathrm{CS})$ can be approximated as (the shaded area in Fig. 3):

$$
\Delta \mathrm{CS}=0.5\left(Q_{\mathrm{off}}+Q_{\mathrm{on}}\right)\left(\tau_{\mathrm{off}}-\tau_{\mathrm{on}}\right)
$$

where $Q_{\text {on }}, Q_{\text {off }}$ are the flows when the ramp meters are on, off respectively; $\tau_{\text {on }}, \tau_{\text {off }}$ are the travel times when the ramp meters are on, off respectively.

If the travel time when the ramp meters are switched off is greater than when they are switched on, then there is an increase of consumers' surplus with metering.

\subsection{Productivity}

Productivity is the ratio of the output of any product to the input that was required to produce that output. For transportation networks, vehicle kilometers traveled (VKT) and the vehicle hours traveled (VHT) are the output and the input respectively, equivalent to a measure of average speed.

$$
P=\frac{\text { output }}{\text { input }}=\frac{\sum \mathrm{VKT}}{\sum \mathrm{VHT}}=\frac{\sum Q L}{\sum Q \tau}
$$




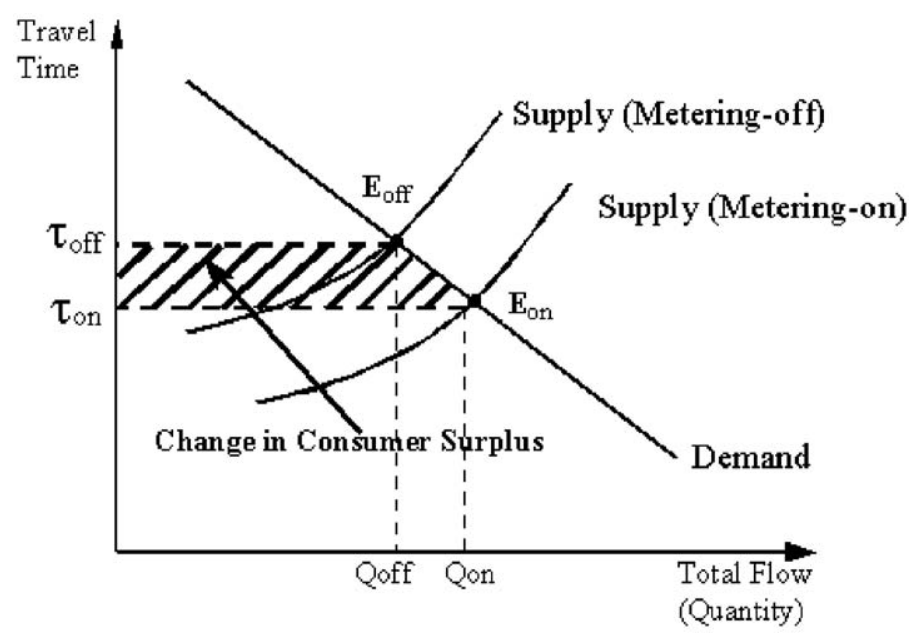

Fig. 3. Measuring changes in consumers' surplus. In Eq. (2), we use a straight line to approximate the actual demand curve between two network equilibrium points: $E_{\text {on }}$ and $E_{\text {off }}$.

The ratio of VKT and VHT is measured for each freeway segment and ramps separately and then added to obtain the productivity of the system for both the metering-on and metering-off cases. Eq. (3) gives a partialfactor productivity measure since VKT is not the only output of a freeway system and VHT is not the only input.

\subsection{Accessibility}

From the transportation planners' perspective, accessibility is defined as the ease of reaching destinations. Weibull (1980) suggests that accessibility is a measure of an individual's ability to participate in activities in the environment. Areas with high congestion often have high accessibility (Levinson and Kumar, 1997). Three functional forms for the travel time decay function are used which are described in Section 6. Freeway accessibility is computed as:

$$
A_{i}=\sum_{j} Q_{j} f\left(\tau_{i j}\right)
$$

where $A_{i}$ is the accessibility of zone $i ; Q_{j}$ are the opportunities at zone $j$, measured using exit flows; $\tau_{i j}$ is the travel time between $i$ and $j$.

\subsection{Travel time variation}

Travel time variation is depicted as the standard deviation of travel times, and used as a measure of travel time reliability. Here we look at two ways to calculate travel time variation: inter-day and intra-day (Bates et al., 1987). Eq. (5) is used to calculate inter-day travel time deviation of all trips with the same OD which start at the same time interval across different days. $V_{t}$ stands for the inter-day travel time variation of this particular OD pair in time interval $t$.

$$
V_{t}=\operatorname{std}\left(\tau_{t, 1}, \tau_{t, 2}, \ldots \tau_{t, n}\right)
$$

where $V_{t}$ is the inter-day travel time variation of trips starting at time interval $t ; \operatorname{std}(\cdot)$ is the standard deviation of $(\cdot) ; \tau_{t, n}$ is the travel time of trips starting at time interval $t$ in day $n$.

The inter-day travel time variation difference $\left(D_{t}\right)$ between the metering-on case $\left(V_{t, \text { on }}\right)$ and the metering-off case $\left(V_{t, \text { off }}\right)$ can be obtained by simply subtracting metering-on values from metering-off values:

$$
D_{t}=V_{t, \text { off }}-V_{t, \text { on }}
$$


Then for trips with the same OD pair, we acquire a vector of inter-day travel time variation differences across different time intervals: $D_{1}, D_{2}, \ldots, D_{t}$. By repeating this process, we acquire the same type of vectors for all OD pairs. The ranges (lower/upper bound) and median values of those vectors can be illustrated graphically with a range/median plot (shown in Section 6).

On the other hand, $v_{n}$ is the intra-day travel time variation of all afternoon peak trips (in different time intervals) with the same OD in day $n$ only. The equation for calculating $v_{n}$ is:

$$
v_{n}=\operatorname{std}\left(\tau_{1, n}, \tau_{2, n}, \ldots \tau_{t, n}\right)
$$

where $v_{n}$ is the intra-day travel time variation of trips in day $n$.

The averages of intra-day travel time variation over all days are first computed separately for metering-on and metering-off cases. Then by comparing these two average values ( $\bar{v}_{\text {on }}$ and $\bar{v}_{\text {off }}$, Eq. (8)) for each OD pair, we ascertain whether ramp meters reduce or increase intra-day travel time variation.

$$
\begin{aligned}
& \bar{v}_{\text {on }}=\operatorname{average}\left(v_{1, \text { on }}, v_{2, \text { on }}, \ldots, v_{n, \text { on }}\right) \\
& \bar{v}_{\text {off }}=\operatorname{average}\left(v_{1, \text { off }}, v_{2, \text { off }}, \ldots, v_{n, \text { off }}\right)
\end{aligned}
$$

\subsection{Demand responses}

Demand responses may not be counted as a measure of effectiveness in a rigorous classification. However, understanding the demand shift due to ramp meters in an integrated transportation system is a key issue to make sense of how the whole system is affected. Previous research has assumed fixed demand when analyzing ramp meters. Ramp metering was first proposed to reduce peak congestion on urban freeways by maximizing throughputs at freeway bottlenecks. For this reason, ramp meters are usually depicted as a short duration (one peak period) demand management device, so its long-term effects on travel demand are, in most cases, overlooked. Moreover, there tends to be a lack of reliable demand data. However, the ramp meter holiday provides us data not previously available to explore the effects of ramp meters on travel demand. Travelers have a full set of possible behaviors in response to ramp metering, summarized in Table 2. Changes in departure time, routes and non-work destinations are shorter-term responses. Responses such as relocation are more drastic and hence are not likely to occur due to ramp meters in the short term and also are unlikely to be captured in the eight-week ramp meter holiday. There is no way to analyze those long-term responses via direct freeway traffic counts. Therefore, we focus on the first three types of behaviors.

Based on 30-s flow counts collected by loop detectors, three freeway system level statistics can be derived: total trips, total vehicle kilometers traveled and average trip length:

Total Trips: Total number of trips entering a freeway in each 30 -s time interval;

Total Vehicle Kilometers Traveled: VKT on a freeway in each 30-s time interval;

Average Trip Length: total VKT divided by total trips.

Then those 30-s total trips, total VKT and average trip lengths are aggregated to seven longer time periods respectively: (1) Morning peak: 6:00-9:00; (2) Afternoon peak: 15:00-19:00; (3) Peak total: (1) + (2); (4) Weekday off-peak: 00:00-6:00 + 9:00-15:00 + 19:00-24:00; (5) Early Morning: 4:00-6:00; (6) Weekdays; (7)

Table 2

Possible responses to ramp metering

\begin{tabular}{ll}
\hline Short-term responses & Long-term responses \\
\hline Switch routes & New modes \\
Change destinations (discretionary trips) & Cancel trips (discretionary trips) \\
Reschedule trips & Alter activity sequences \\
& Change job/house location \\
\hline
\end{tabular}


Weekend. The median values of the total trips, total VKT and average trip lengths in the above seven durations across the study period are then computed and compared in various ways. The "\%Change" results presented in Section 6 are percentage changes from values with ramp metering control to values without ramp metering control. By comparing results in different time periods, we are able to answer many key questions about how travel demand responds to ramp metering.

\section{Measuring travel times}

This section summarizes the methodology to compute speeds and travel times on entrance ramps, freeway mainline segments, and OD pairs on a freeway with and without ramp meters from traffic data collected by loop detectors.

Throughout the studied peak periods, all ramp arrival detectors have low occupancy readings, indicating no queue spillover effects to local connecting streets. This assures that the delays at on-ramps represent total delays caused by ramp meters. Given the arrival $\left(q_{k}\right)$ and departure $\left(Q_{k}\right)$ rates collected in each control interval $k$, it is possible to identify the waiting time in queue $\left(d_{v}\right)$ each individual vehicle experiences at on-ramps by a queuing analysis (Newell, 1982). This waiting time will be simply referred to as ramp delay for the remainder of this paper because the free-flow travel time from the ramp arrival detector to the departure detector is usually very short. (Discussions on distinguishing "delay" and "waiting time in a queue" can be found in Lawson et al., 1997; Lovell and Windover, 1999). For the queuing analysis, the ramp departure distribution is assumed to be uniform in each control interval due to the presence of ramp meters. The arrival pattern is simulated using a Poisson process, which allows for bunching of vehicles and implies a negative exponential arrival distribution. Individual ramp delays can be aggregated to average delay at on-ramp $r$ in interval $k\left(d_{r, k}\right)$.

The freeway mainline is divided into segments with uniform flow characteristics (i.e. no intervening on- or off-ramps in each segment), where inductive loop detectors provide flow and occupancy information in 30-s intervals. The standard textbook equation used to compute space mean speed from single loop flow and occupancy data requires information of the effective vehicle length. The MnDOT Metro Division Traffic Management Center used speed data measured directly by laser guns during afternoon peak periods to calibrate the effective vehicle length and sensitivity settings at individual detection stations. Although the true effective vehicle length at a detection station varies with the real-time traffic composition, the calibrated average length should be accurate enough for the purpose of this study. Space mean speeds calculated for individual lanes at a detection station should be weighted by density to produce the mean speed of the station. It is noted in our study that volume-weighted mean speeds are almost the same as density-weighed speeds (differences $<1 \mathrm{~km} / \mathrm{h}$ ), even when freeways are congested. The weighted speed at a detection station is assumed to be the average speed of the freeway segment where the detection station is located. If there is no detection station in a segment, the speed at the nearest station will be used (though this kind of situation rarely occurs on selected freeway segments). Once the average speed and the length of each freeway mainline segment are determined, travel time $\left(\tau_{i, k}\right)$ can be easily derived.

Ramp delays and travel times on freeway mainline segments need to be synchronized to produce total travel time between origin-destination pairs (origins: starting points of on-ramps; destinations: off-ramps):

$$
\tau_{i, j, k}=d_{r, k}+\tau_{i, k+x_{1}}+\tau_{i+1, k+x_{2}}+\cdots+\tau_{j-1, k+x_{j-i}}
$$

where $\tau_{i, j, k}$ is the travel time from origin $i$ to destination $j$ for vehicles departing in time interval $k ; d_{r, k}$ is the delay at on-ramp $r$ (located at origin $i$ ) in time interval $k ; \tau_{i, k+x}$ is the travel time on freeway segment $i$ in time interval $(k+x), x$ is the number of time intervals it takes for vehicles to travel from origin $i$ to the current freeway mainline segment.

OD travel times throughout a peak period can be summarized in a two-dimensional matrix (time interval by OD pairs). Provided OD distances, an OD speed matrix can be derived from the OD travel time matrix. These two mobility matrices, along with ramp delays at on-ramps, travel times on freeway mainline segments, and flow data, are then used to compute various performance measures introduced in Section 2 for both the metering-on and metering-off cases. 


\section{Minnesota algorithm}

The Minnesota Department of Transportation operated ramp meters before the shut-off experiment under a zonal control strategy that divided freeways into zones terminating at bottlenecks. The number of vehicles in each zone at a given time was constrained by the capacity of the bottleneck. Ramp metering was used to limit those vehicles. The metering zone equation can be expressed as:

$M+F=X+B+S-A-U$

s.t. incident override and occupancy control

where $M$ is the sum of metered local access ramp flows (controlled variable); $F$ is the sum of metered freeway to freeway access ramp flows (controlled variable); $X$ is the sum of exit ramp flows (measured variables); $B$ is the downstream bottleneck flow at capacity (constant); $S$ is the space available within the zone (flow based on a measured variable); $A$ is the upstream mainline flow (measured variable); $U$ is the sum of unmetered entrance ramp flows (measured variable);

Any measured variation in $(X+B+S-A-U)$ is equaled by a controlled variation in $(M+F)$. Each individual variable, except $S$ (set to be zero indicating no available space in the zone), in the zone Eq. (10) is assigned a 1-h flow derived from historical detector data. When these historical flows are placed in Eq. (10) an exact balance may not appear. For this reason, a minor adjustment to the incoming flow $(A)$ is made to balance the new equation and the values in this balanced Eq. (11) are the target flows:

$$
M_{\mathrm{T}}+F_{\mathrm{T}}=X_{\mathrm{T}}+B_{\mathrm{T}}+S_{\mathrm{T}}-A_{\mathrm{T}}-U_{\mathrm{T}}
$$

where T means target flows; $S_{\mathrm{T}}$ is set to zero.

Each metered ramp is assigned six metering rate factors. On local access ramps, these rates over a 5 -min time period range from 0.5 to $1.5(0.5,0.7,0.9,1.1,1.3$ and 1.5$)$ and on freeway-to-freeway ramps, from 0.75 to 1.25 $(0.75,0.85,0.95,1.05,1.15,1.25)$. The narrower range for freeway-to-freeway ramps reflects the fact that these ramps carry much higher flows and a smaller percentage change provides the desired numerical flow change. The control variable $(M+F)$ is then expressed as the products of the target flows and metering rate factors. For example, at the most restrictive rate factor (rate 6), $M=0.5 M_{\mathrm{T}}$ and $F=0.75 F_{\mathrm{T}}$. The selection of which one of the six rate factors to use for a metering zone is then determined by a comparison of the on-line measured variables $(X+B+S-A-U)$ to a series of thresholds. For instance, if $0.6 M_{\mathrm{T}}+0.8 F_{\mathrm{T}}<(X+B+S-$ $A-U)<0.8 M_{\mathrm{T}}+0.9 F_{\mathrm{T}}$, rate 5 will be used. At rate $5, M=0.7 M_{\mathrm{T}}$ and $F=0.85 F_{\mathrm{T}}$.

Whether any rate is the final metering rate factor is still subject to incident override and occupancy control. For more details on the Minnesota algorithm, readers may refer to Minnesota Department of Transportation (MnDOT) $(1996,1998)$ and Bogenberger and May (1999).

\section{Data}

The raw data are archived 30-s flows and occupancies provided by the Metro Division Traffic Management Center (TMC) of the Minnesota Department of Transportation. All data used in this study have passed TMC's continuity test for detector readings, which is an algorithm based on flow conservation to check the accuracy of detector data. In choosing the study locations and the study period, we follow these criteria:

(1) The time-space domain must be free of congestion at the beginning and the end of the study period. Thus the flow conditions within selected freeway sections during the study period will not be affected by further downstream queues.

(2) Data must be complete. There are no malfunctioning detectors in the selected freeway sections during the study period.Under criteria (1) and (2), the study period was chosen to be the afternoon peak from 14:30 to 19:30 and only four freeways are qualified: I-494 outer-loop (eastbound and southbound), I-494 inner-loop (westbound and northbound), TH169 northbound and TH62 westbound (see Fig. 4). Many other freeways did not qualify because there were no working on-ramp queue detectors which could 


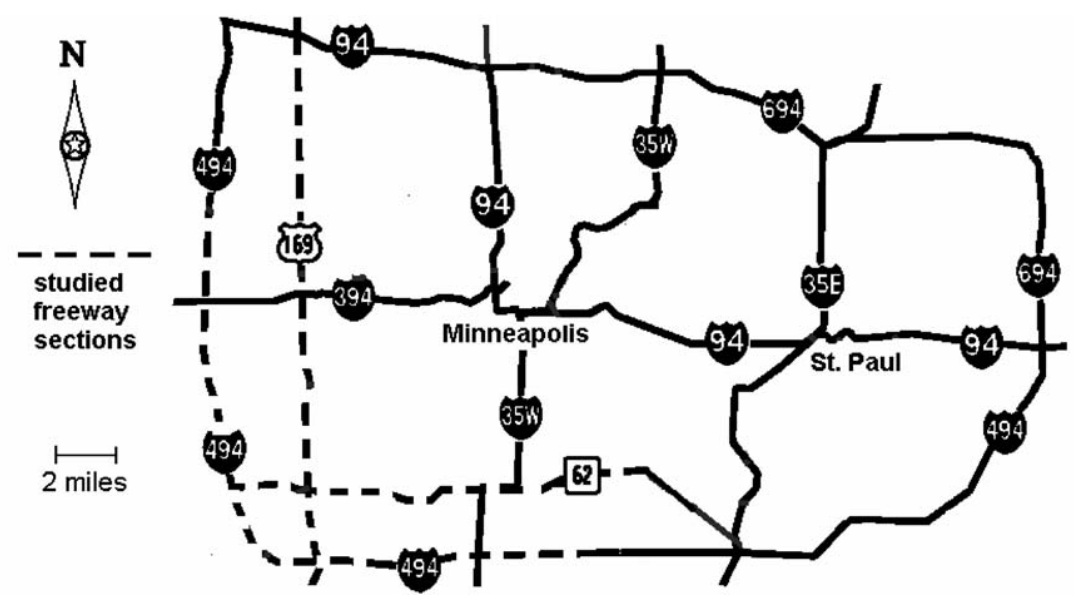

Fig. 4. Study locations.

provide arrival data in computing ramp delays for the metering-on case. Even on the selected four freeways, there were still some on-ramps where queue detectors either over-count or under-count vehicles. These on-ramps are excluded from the analysis.

(3) Only use the data collected during the last six weeks of the holiday to avoid the noisy and unrepresentative travel behaviors immediately after shut-off. Data collected in the corresponding six weeks (from the fourth week in October to the first week in December) in year 1999 are used to compute performance measures for the metering-on case in order to avoid impacts of seasonal demand fluctuation.

(4) "Bad-weather" days were excluded from the two six-week periods (metering-on and metering-off). Days with more than $0.4 \mathrm{in}$. of hourly precipitation (rain or snow) in any 1-h duration in the studied afternoon peak period are "bad-weather" days. For example, if the Tuesday in the first week of October 2000 is identified to be a "bad-weather" day, this Tuesday and the corresponding Tuesday in October 1999 will both be excluded from the analysis, no matter the weather condition on the 1999 Tuesday. We only considered precipitation since freeway capacities in the Twin Cities were found to be most sensitive to the precipitation among all weather factors (wind, temperature, sky cover, etc.) (Ries, 1980). Weather data were from NOAA hourly weather reports collected at Minneapolis and St. Paul Airport Station. While it would be interesting to examine bad weather conditions, we are unable to separate seasonal effects, weather effects and control effects.

(5) Days with recorded lane-blocking accidents during the study periods on the selected freeways were also excluded from the analysis. The TMC freeway accident database stores fairly detailed information about each reported accident, such as the start time, clearance time, number of lanes blocked, and incidence type (crash, stalled car etc.). After the above data-filtering process, we now have a data set collected on 29 days out of six weeks for both metering-on and metering-off cases on selected freeways (on TH62, 27 days because two more days are excluded due to malfunctioning detectors). Various performance measures are computed based on this data set.

\section{Results}

\subsection{Mobility, equity, consumers' surplus, productivity and accessibility}

The computed mobility (travel time, speed), equity, consumers' surplus, productivity and accessibility measures on the four selected freeways are very similar. Therefore, in the following presentation, we will only discuss in detail the results obtained on a representative freeway, TH169. Important statistics are tabulated for all four studied freeways.

First the relationship between mobility and equity with and without ramp meters is estimated. Figs. 5 and 6 illustrate the trends in the change of mobility and equity with and without metering on TH169. The mobility 


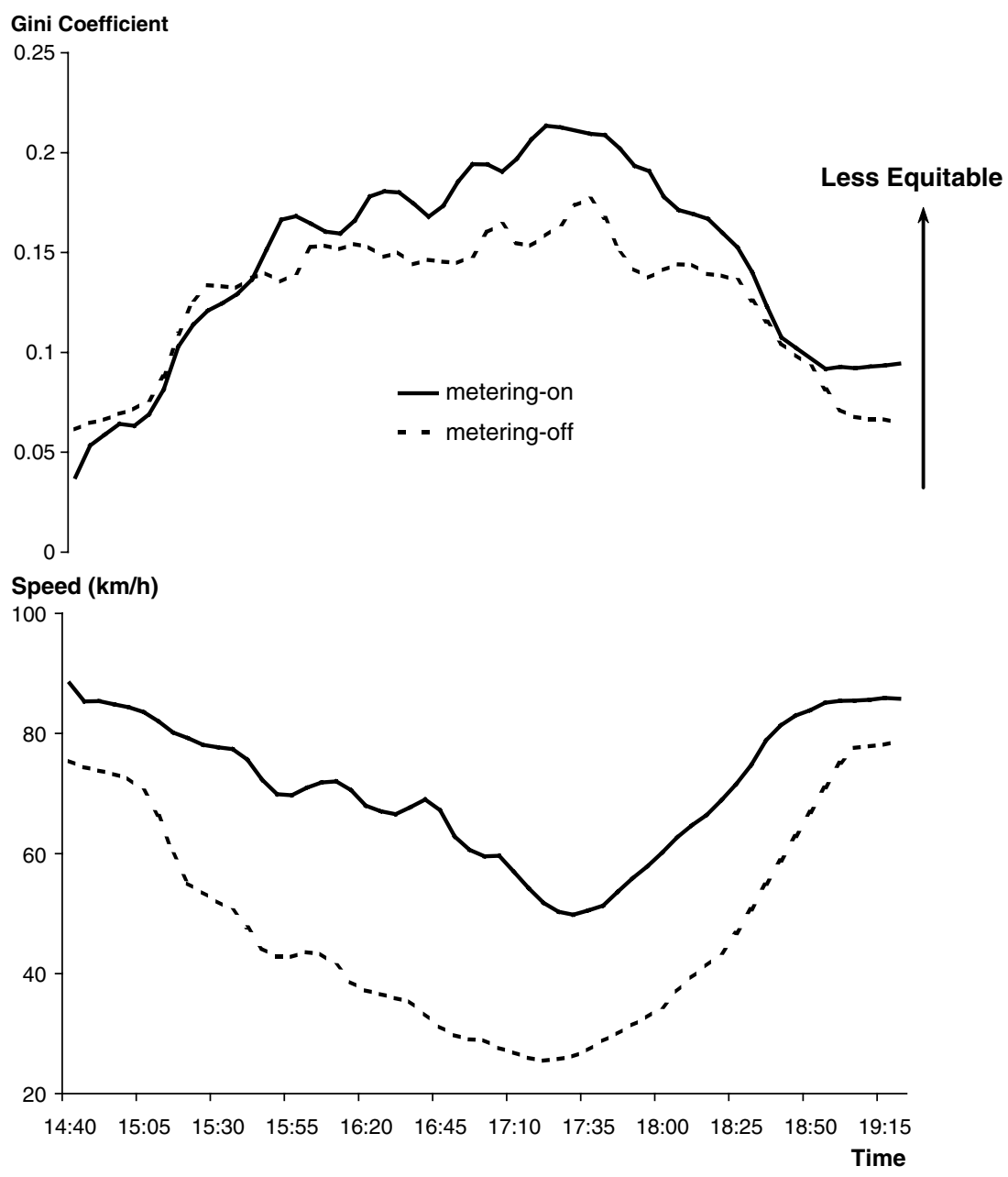

Fig. 5. Spatial equity and mobility (speed) on TH169.

and equity values in the graph are averaged mobility and equity measures over all 29 days. For instance, to obtain spatial speed/Gini coefficient for time interval $k$ in Fig. 5, we compute speeds/Gini coefficients in time interval $k$ for all 29 days. It is the average of these speeds/Gini coefficients that is presented in the graph. Fig. 5 looks at spatial equity vs. spatial mobility, and shows worsening equity and mobility as the peak is reached. More interesting, the trade-off between mobility and spatial equity is evident. That is the metering-on case has better mobility but worse spatial equity compared to the metering-off case.

In Fig. 6, temporal equity vs. temporal mobility, some short trips (those on the left side of the graph) actually are hurt in both mobility and temporal equity by ramp metering, while the longest trips (those on the right side) benefit the most. Thus it is fair to say that drivers making shorter trips are losers and those making longer trips are winners under the ramp metering control policy.

What ramp metering delivers in term of mobility and equity for all OD pairs throughout the afternoon peak period can be shown by the comparison of spatial-temporal mobility and equity of the two cases in Table 3 . The spatial-temporal mobility measures presented in Table 3 are essentially the same as overall system performance measures which appear frequently in other freeway performance studies. Previous studies indicate that ramp meters can increase the mobility of freeway networks (Taylor and Meldrum, 2000; Haj-Salem and Papageorgiou, 1995, among others), which is confirmed here. With ramp metering, average travel time per kilometer of travel (taking ramp delay into account) on TH169 decreases from $104 \mathrm{~s}$ to $66 \mathrm{~s}$ while average travel speed increases from 48 to $71 \mathrm{~km} / \mathrm{h}$. The spatial-temporal equity results are mixed, favoring neither the 


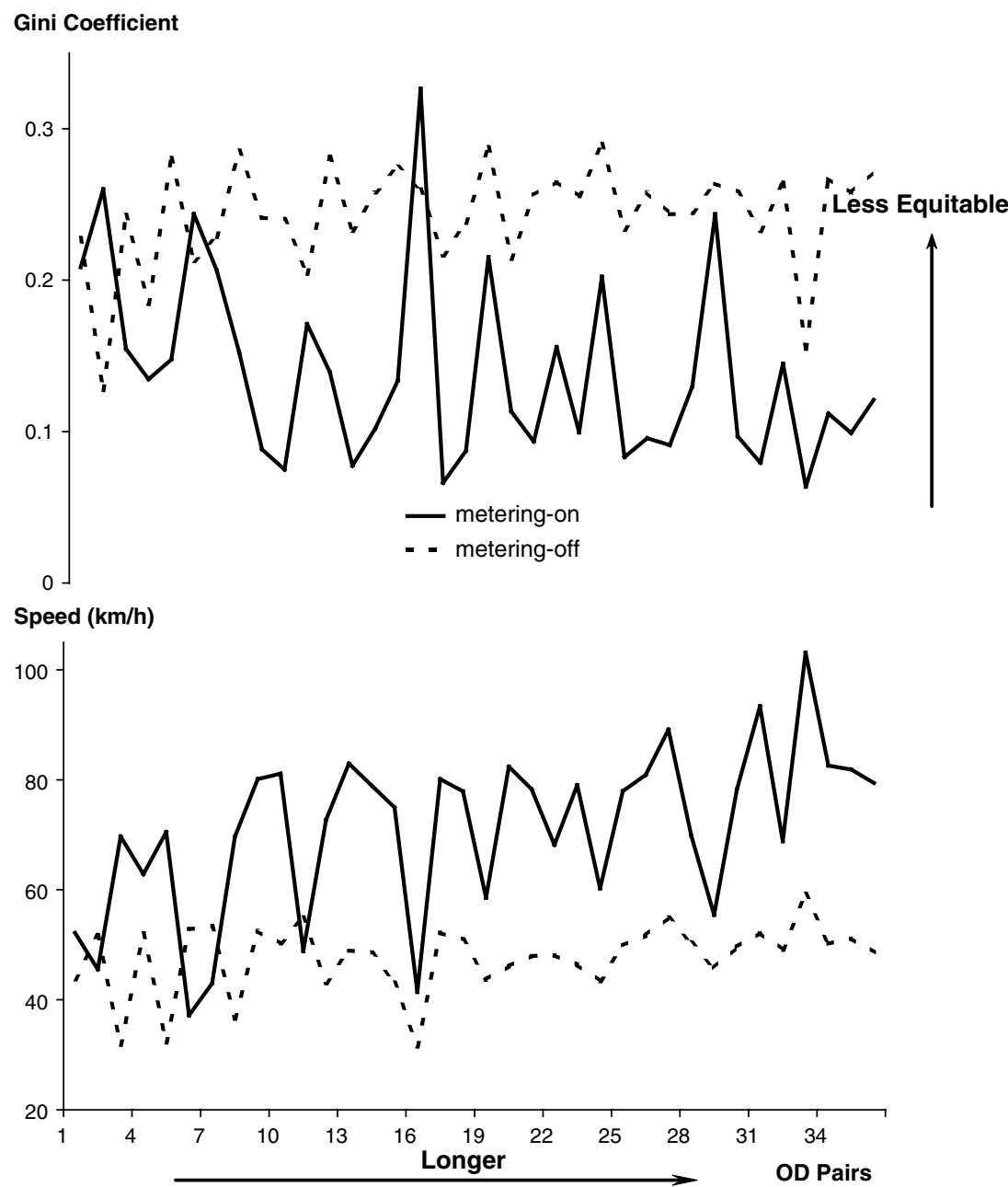

Fig. 6. Temporal equity and mobility (speed) on TH169.

Table 3

Spatial-temporal equity and mobility

\begin{tabular}{|c|c|c|c|c|c|}
\hline \multirow[t]{2}{*}{ Freeways } & & \multicolumn{2}{|c|}{ Travel speed $(\mathrm{km} / \mathrm{h})$} & \multicolumn{2}{|c|}{ Travel time $(\mathrm{s} / \mathrm{km})$} \\
\hline & & Metering-off & Metering-on & Metering-off & Metering-on \\
\hline TH169NB & $\begin{array}{l}\text { Mobility } \\
\text { Gini }\end{array}$ & $\begin{array}{l}48 \\
0.269\end{array}$ & $\begin{array}{l}71 \\
0.188\end{array}$ & $\begin{array}{l}104 \\
0.285\end{array}$ & $\begin{array}{l}66 \\
0.284\end{array}$ \\
\hline I494NW & $\begin{array}{l}\text { Mobility } \\
\text { Gini }\end{array}$ & $\begin{array}{l}65 \\
0.156\end{array}$ & $\begin{array}{l}78 \\
0.170\end{array}$ & $\begin{array}{l}63 \\
0.178\end{array}$ & $\begin{array}{l}57 \\
0.255\end{array}$ \\
\hline I494SE & $\begin{array}{l}\text { Mobility } \\
\text { Gini }\end{array}$ & $\begin{array}{l}53 \\
0.241\end{array}$ & $\begin{array}{l}75 \\
0.141\end{array}$ & $\begin{array}{l}97 \\
0.285\end{array}$ & $\begin{array}{l}62 \\
0.239\end{array}$ \\
\hline TH62WB & $\begin{array}{l}\text { Mobility } \\
\text { Gini }\end{array}$ & $\begin{array}{l}75 \\
0.097\end{array}$ & $\begin{array}{l}83 \\
0.127\end{array}$ & $\begin{array}{l}51 \\
0.112\end{array}$ & $\begin{array}{l}50 \\
0.205\end{array}$ \\
\hline
\end{tabular}

metering-on case nor the metering-off case. This can be explained by the results presented in the previous two paragraphs: (1) spatial equity decreases with ramp metering; (2) temporal equity of short trips decreases with ramp metering; (3) temporal equity of long trips increases with ramp metering. 
Daily productivity, changes in consumers' surplus and accessibility are derived first using the method introduced in Section 2. Then the average daily productivity, changes in consumers' surplus and accessibility over all 29 day are computed and presented in Tables 4-6 respectively.

Table 4 shows productivity, the vehicle kilometers of travel per vehicle hour of travel on all four studied freeways. Productivity on freeway mainline increases with ramp metering but productivity at on-ramps decreases. Combining freeway mainline with on-ramps gives a system productivity measure (mainline $\mathrm{VKT}+\operatorname{ramp} \mathrm{VKT}) /($ mainline VHT + ramp VHT). The system productivity is improved immensely by ramp metering. The percentage increase on TH169 is 53\%.

Table 5 summarizes changes in consumers' surplus on all four studied freeways. The changes in consumers' surplus for each individual freeway mainline segment on TH169 are summed to get a benefit from metering of 2534 vehicle hours. The change in consumers' surplus on entrance ramps is found to be -237 vehicle hours. As expected, ramp meters significantly reduce the consumers' surplus of entrance ramps. However, ramp meters benefit freeway mainline more than they harm entrance ramps, so an overall positive change in consumers' surplus of 2298 vehicle hours is recorded.

Three different accessibility models were applied to TH169. The first is a classic gravity model, the second a model estimated for freeways in the Twin Cities, and the third from a regional gravity model estimated by the primary author for Washington, DC (Levinson and Kumar, 1995). For all the three models, accessibility increases with ramp metering, as shown in Table 6.

\subsection{Travel time variation}

Inter-day travel time variation results for four studied freeways are shown graphically in Fig. 7 (range/median plots). It is obvious that for most OD pairs (103/127: 26/45 OD pairs $\leqslant 5 \mathrm{~km}, 77 / 82$ OD pairs $>5 \mathrm{~km})$, inter-day travel time variability is reduced by implementation of the ramp metering system $(t$ tests of

Table 4

Productivity

\begin{tabular}{llll}
\hline Freeways & Productivity $(\mathrm{km} / \mathrm{h})$ & & $\%$ Change \\
\cline { 2 - 4 } & Metering-off & Metering-on & 53 \\
\hline TH169NB & 46 & 71 & 22 \\
I494NW & 67 & 83 & 41 \\
I494SE & 54 & 78 & 12 \\
TH62WB & 80 & 90 & \\
\hline
\end{tabular}

Table 5

Changes in consumers' surplus

\begin{tabular}{llll}
\hline Freeways & \multicolumn{2}{c}{ Average daily changes in consumers' surplus (vehicle * hours) } & System \\
\cline { 2 - 4 } & On-ramps & Freeway mainline & 2298 \\
\hline TH169NB & -237 & 2534 & 1363 \\
I494NW & -189 & 1551 & 2445 \\
I494SE & -86 & 2535 & 328 \\
TH62WB & -20 & 348 & \\
\hline
\end{tabular}

Table 6

Accessibility

\begin{tabular}{|c|c|c|c|c|c|c|c|c|c|}
\hline \multirow[t]{2}{*}{ Freeways } & \multicolumn{3}{|c|}{ Model 1: $f\left(C_{i j}\right)=1 / t_{i j}^{2}$} & \multicolumn{3}{|c|}{ Model 2: $f\left(C_{i j}\right)=\mathrm{e}^{-0.00189 t_{i j}}$} & \multicolumn{3}{|c|}{ Model 3: $f\left(C_{i j}\right)=\mathrm{e}^{-0.08 t_{i j}}$} \\
\hline & Off & On & $\%$ & Off & On & $\%$ & Off & On & $\%$ \\
\hline TH169NB & 1064 & 2073 & 94 & 47,425 & 47,125 & 0 & 21,111 & 27,521 & 30 \\
\hline I494NW & 2064 & 3127 & 52 & 35,509 & 37,733 & 6 & 17,997 & 19,895 & 11 \\
\hline I494SE & 1540 & 2865 & 86 & 38,225 & 39,969 & 5 & 16,607 & 21,714 & 31 \\
\hline TH62WB & 2554 & 3262 & 28 & 45,896 & 46,666 & 2 & 30,644 & 32,147 & 5 \\
\hline
\end{tabular}

On: with ramp metering; Off: without ramp metering; \%: percentage changes. 
$V_{\text {off }}-V_{\text {on }}>0$ are statistically significant at level 0.01 ). Freeway peak hour travel reliability increases. However, for extremely short trips $(\leqslant 5 \mathrm{~km})$, it is hard to say whether ramp meters improve or reduce inter-day travel time variations. Fig. 8 illustrates intra-day travel time variation results with two curves representing the metering-on and metering-off cases respectively. Although the intra-day travel time variation reductions caused by ramp meters differ by freeway segment, clearly ramp meters play a positive role in reducing intra-day travel time variation. As in the inter-day results, intra-day travel time variation of long trips is reduced more significantly than those of short trips.

During the ramp meter holiday, only variation of freeway mainline conditions cause variability in travel times. But for a metered freeway, ramp delay variability also contributes to the overall trip travel time variation. The contribution of ramp delay variability to the overall travel time variation can be separated out. Results show that for a significant number of trips (42/131 OD Pairs), inter-day travel time variation of these trips could be reduced by more than $50 \%$ with a metering strategy that ensured the same ramp delay at the same time-of-day, across days. In other words, on different days, the Minnesota algorithm results in quite different ramp delays even during the same time intervals. This finding is not surprising because the demand patterns usually vary from day to day. But it does suggest that there is a potential to further improve travel reliability by keeping metering rates more steady across days. However, implementing such an algorithm may only slightly reduce the average travel time. How mobility and reliability trade-off in a ramp control strategy is an interesting future research topic.

Assuming that all OD pairs have the same number of trips, the difference in overall average inter-day travel time variation is $1.82 \mathrm{~min}$. That means the implementation of ramp metering control can reduce $1.82 \mathrm{~min}$ of travel time standard deviation. Black and Towriss (1993) and Small et al. (1995, 1999) estimated a so-called "reliability ratio" (ratio of cost of standard deviation to mean travel time when scheduling costs are not separately considered) and consensus results of $0.7,1.27$ and 1.31 were obtained. Using the unit cost of travel time uncertainty - \$0.21 per minute of standard deviation which was estimated by Small et al. (1999) from a stated preference passenger survey in Los Angeles, ramp metering can save $\$ 0.38$ for each freeway trip in terms of increased travel certainty.
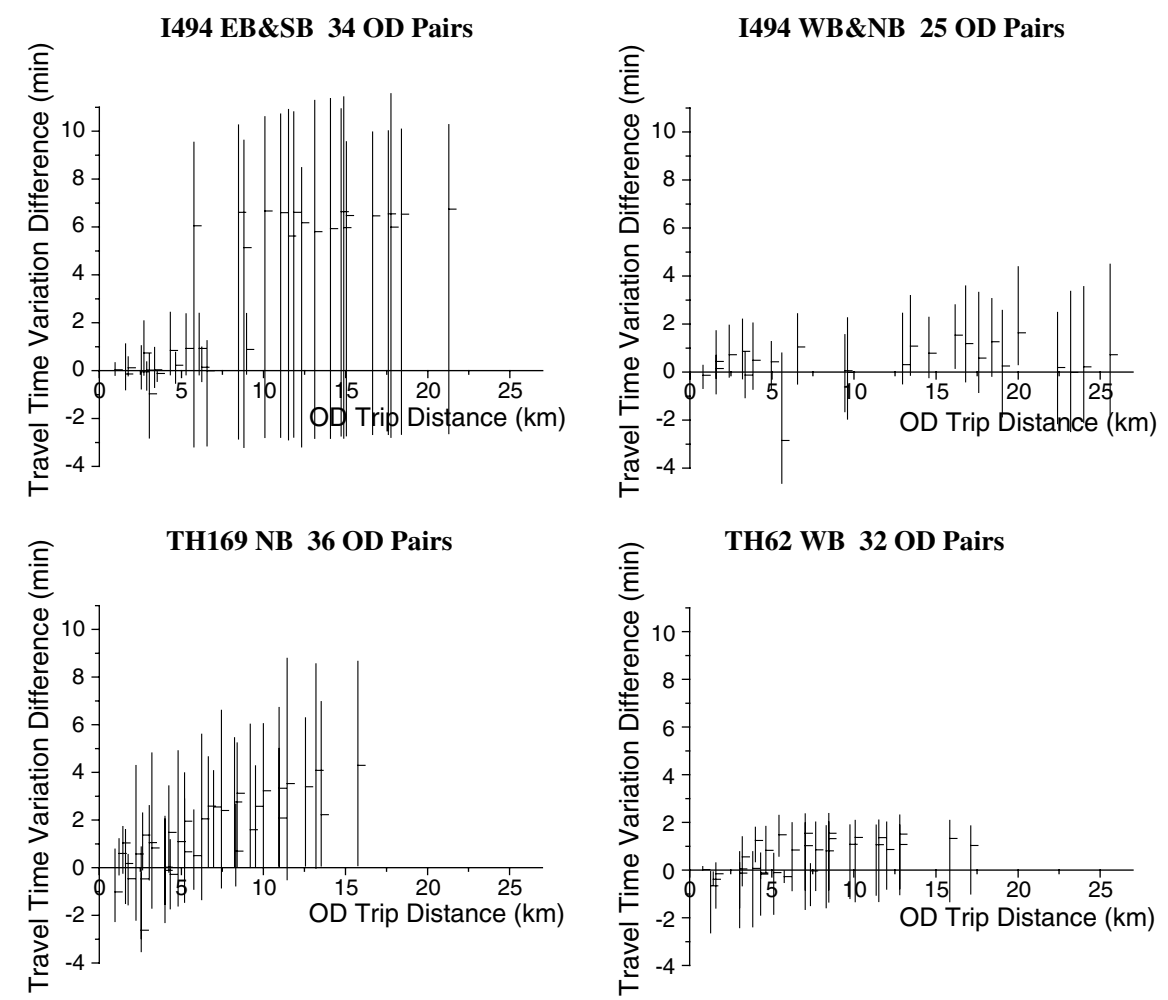

Fig. 7. Inter-day travel time variation difference of each freeway without ramp meters - with ramp meters $\left(V_{\text {off }}-\mathrm{V}_{\text {on }}\right)$. 

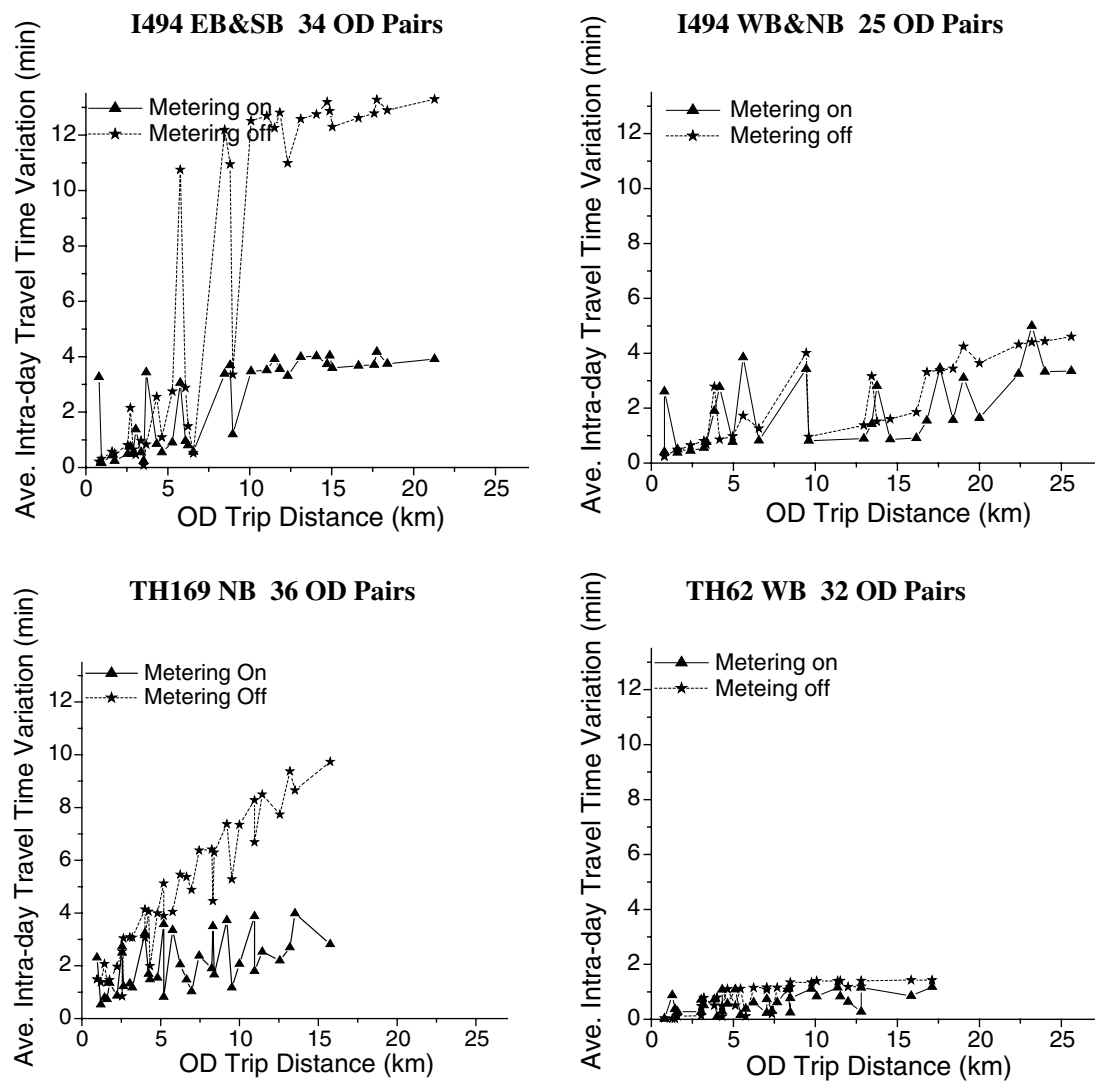

Fig. 8. Intra-day travel time variation: with/without ramp metering control.

\subsection{Demand responses}

Because the ramp meter shutdown experiment was carried out in 2000 and the chosen corresponding metering-on period is in 1999, our results will be drivers' response to metering holiday. There is no reason to believe that the results are not reversible and it is expected that travelers' response to the return of ramp meters would simply be the opposite.

\subsubsection{Spreading of the peak}

The ratio of the peak 15-min flow to the peak hour flow is widely used to represent the spreading of the peak. This can also be done using loop detector counts by aggregate traffic flows at 15-min time intervals. However, this is only one way to look at peak spreading and some other methods are also useful. Here, we make two comparisons. First, we compare the change of total traffic flows (total trips) in the early morning period and those in the morning peak. It is obvious from Fig. 9a that travelers respond to the shut-off of ramp meters by departing earlier in the morning to avoid congestion in the morning peak periods. Secondly, we compare the total vehicle kilometers traveled in two peak periods with those in two off-peak periods in Fig. 9b: weekday off-peak and weekends. When ramps are unmetered, relatively more travel is made during off-peak hours while less travel is made in the peak period. Many trips that occur in the peak periods with metering are pushed entirely to the off-peak periods without metering, generally weekday off-peak hours. The small increase in VKT on weekends is in tune with typical traffic growth.

\subsubsection{Non-work trips}

While work trips are characterized by a strongly desired arrival time and a fixed destination, non-work trips can more easily shift time and location. Research comparing the United States Nationwide Personal 

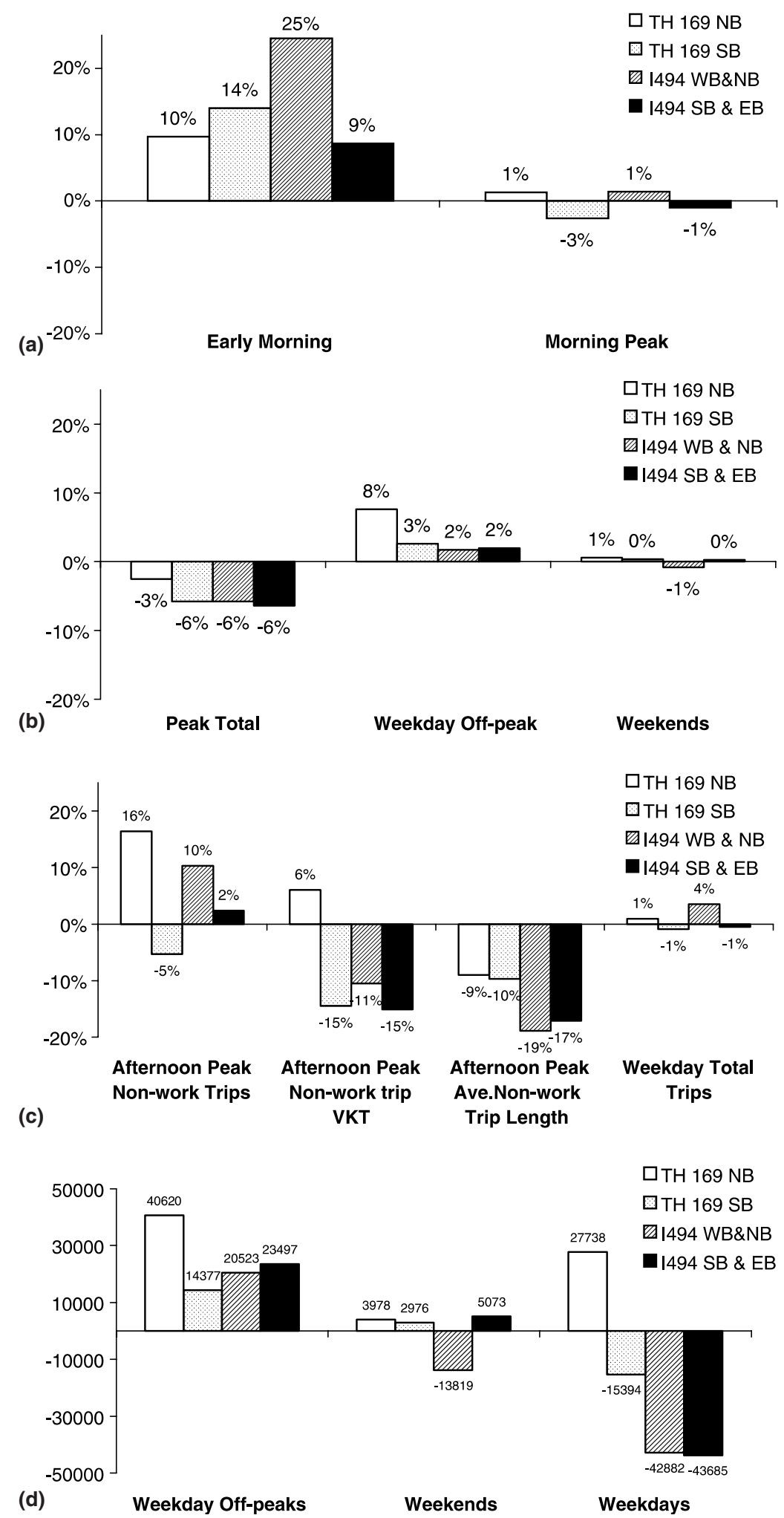

Fig. 9. Demand responses to ramp meters. (a) Early morning and morning peak percentage change of total trips. (b) Peak total and offpeak percentage change in total VKT. (c) Afternoon peak non-work trip percentage changes in total trips, total VKT and average trip length. (d) Changes in total VKT of weekday off-peaks, weekends and weekdays. 
Transportation Survey reported a significant amount of discretionary travel (Pisarski, 1992). Therefore, it is rather important to explore how non-work trips react to the shut-off of ramp meters. Also given that previous mobility results show different effects of ramp meters on short trips and long trips, it is also of high interest to separate out short non-work trips and long work trips to see their different demand responses.

A direct traffic count can reflect trip purpose only if it is collected at certain locations, such as a street to a recreation center. However, some inferences can be made based on the assumption that morning peak trips are dominated by work trips but afternoon peak trips consist of both work trips and non-work trips. Non-work trips, such as shopping and visiting are more likely to happen in the afternoon than in the morning. Analysis in Montgomery County, MD also confirms this point (Levinson and Kumar, 1994): about 80\% of travel during the morning peak is classified as work trips; while in the afternoon peak period, work travel constitutes only $50 \%$ of all trips. Then the difference between the morning peak and the afternoon peak in terms of total trips and total vehicle kilometers traveled can be ascribed to a large extent to non-work trips that occur in the afternoon peak. For instance, the afternoon peak non-work trips on a northbound freeway will be the difference between the total afternoon peak northbound trips and the total morning peak southbound trips, because work trips reverse directions between morning and afternoon.

As expected, afternoon peak total trips and total VKT are always greater than those in the morning peak period, largely explained by the additional non-work travel during the afternoon peak period. There are more non-work trips in the afternoon peak period as a result of shutting off ramp meters (see Fig. 9c). The increase in afternoon non-work trips cannot be explained by the weekday trip growth rate, the four bars from the right end in Fig. 9c. It is even more interesting to look at the change in total VKT. It decreases despite the increase in total trips. The only explanation is that as a result of the holiday, long peak-period non-work trips are discouraged while short non-work trips are encouraged. On average, during the holiday people are making more but shorter non-work trips in the peaks, exhibited by the decrease of average non-work trip length. Although this effect for all afternoon trips as a whole is mitigated to some extent by the inelasticity of work-trips, this trend of increasing total trips but decreasing total VKT still can be seen for the whole afternoon peak-period.

Travelers reschedule their short non-work trips to the peak period and defer their long non-work trips to off-peak times when the ramp meters are off. There is no evidence that travelers change their weekend short non-work trips to weekday peaks. So, the additional short non-work trips in the afternoon peak without metering should occur during the weekday off-peak with metering. However, things are not so straightforward when we think about when those long non-work trips are rescheduled. They can then occur in weekday offpeak hours or weekends instead. Fig. 9d shows the changes in total VKT for these two time periods. Considering that the loss of short non-work trips should decrease the total VKT in the weekday off-peaks and that the increase of total VKT resulting from peak spreading only constitutes a small part of the total increase of VKT in the weekday off-peaks, we draw the conclusion that many long non-work trips are redistributed to weekday off-peak hours or vanish entirely.

\subsubsection{Changing routes and destinations}

Fig. 9b shows that freeways carry less traffic in peak periods without metering and people reschedule their trips to weekday off-peak periods. If all trips pushed out from peak period are rescheduled to occur during offpeak hours, the total change in VKT with/without ramp meters should be non-negative taking traffic growth into account. However, if we take a look at the change in total weekday travel (see Fig. 9d), the total weekday VKT decreases on most freeways. It is evident that travelers react to congestion without metering not only by rescheduling their trips but also by changing routes and destinations. They may switch to a local arterial, a less congested freeway or even a less congested direction. Our results cannot provide more details. In general, unmetered freeways take less travel, but not much less.

\section{Conclusions}

This paper analyzed ramp metering in the Twin Cities using a number of measures of effectiveness. In general, the findings were favorable to ramp metering on four studied freeways.

Prior to October 2000, the Minnesota ramp meter control strategy had been focused on the freeway mainline, ignoring delay on ramps. This theory of freeway ramp metering argues that ensuring higher flows on free- 
ways guarantees lower flows elsewhere on the road network. The more vehicles able to use the freeways, the fewer that will burden local streets. By the objectives the ramp meters were intended to satisfy, maximizing freeway throughput at selected bottlenecks, this study confirms that the facility performs better in the presence of operating ramp meters than in their absence. The change in consumers' surplus was positive while at the same time, the productivity of the system almost doubled on some freeways. Travel speeds (after considering ramp delays) and flows are consistently higher with ramp metering than without. While this is logical if the intention is to maximize freeway throughput, it does not necessarily maximize user satisfaction of the system, especially when the ramp delays are far from being evenly distributed. For instance, spatial equity is worse with ramp metering.

Ramp meters are particularly helpful for long trips relative to short trips. This study on TH169 and three other freeways shows that trips more than 3 exits in length benefit, while many trips 3 exits or less are hurt by ramp meters. Overall, longer trips benefit more than shorter trips. Originally, freeways (the interstate highway system) were designed to serve intercity not local traffic. However freeways have evolved to serve commuters. Whether reserving the freeways for long trips is still an appropriate objective is an important public policy debate.

Other possible objectives or constraints, such as ensuring that delay is distributed as evenly as possible, are not achieved by the ramp metering control in place before this study. Consider for instance traffic signals on streets. If a minor road meets a major road, and the major road is operating at capacity, it might be most efficient (in terms of minimal total delay) to give $100 \%$ of the green time to the major road and $0 \%$ to the minor road. This is not done. Traffic signals alternate back and forth in part to ensure some equity, so that travelers on the minor road do not have an excessive wait. Generally cycle lengths on roads at capacity are under 3 min, though this varies. A similar limit on individual delay, even at the expense of overall freeway efficiency, may be necessary for ramp meters to satisfy equity considerations. The trade-off between efficiency and equity from a theoretical perspective is discussed in Zhang and Levinson (2004). Furthermore, if efficiency is defined more broadly, for instance, maximizing the utility of travelers, recognizing a non-linear value of time, that constraint may be even more essential. So while the Minnesota algorithm may in generally be better than no metering at all, there may be other control strategies that perform better still on a wide variety of performance measures. A method of balancing efficiency and equity of ramp meters is proposed based on this school of thoughts in a separate study (Zhang and Levinson, 2005). Future studies may also evaluate other operational ramp control strategies, e.g. ALINEA (Papageorgiou et al., 1991) using the performance measures developed in this study.

Ramp metering was designed to improve freeway traffic flow and safety. While it generally does both (see Cambridge Systematics, 2001, for a discussion of safety effects), it also has the effect of improving travel time reliability for long trips. This should be captured in the analysis of ramp metering benefits.

Travelers react to the congestion resulting from the ramp metering shut-off by departing earlier in the morning and rescheduling their trips to weekday off-peaks, which shows a certain amount of peak spreading. Travelers also change routes and destinations. In general, freeways handle fewer vehicle kilometers when there is no ramp metering, but not much fewer. A unique demand response to ramp metering appears on non-work trips. Although there are more non-work trips during the afternoon peak period in general, total afternoon peak non-work trip VKT decreases when ramp meters are shut off. The absence of ramp meters discourages long peak-period non-work trips, which are deferred to weekday off-peak hours. On the other hand, short non-work trips are encouraged to occur in the peak period without meters. On average, people make more but shorter non-work trips in the afternoon peak periods on unmetered freeways. This is because long distance trips save time at the expense of short trips when freeways are metered as mentioned before.

Finally, it must be remembered that ramp metering alone cannot be expected to mitigate traffic growth. Given the under-investment in highway capacity relative to growth in demand, and the present unwillingness to affect demand through pricing or other measures, congestion is inevitable. While ramp meters can help at the margins, delaying the onset of freeway breakdowns and by making freeways flow smoother, they cannot eliminate congestion entirely.

\section{Acknowledgments}

This research was part of the project Measuring the Equity and Efficiency of Ramp Meters funded by the Minnesota Department of Transportation. The authors would like to thank the Center for Transportation 
Studies and International Road Federation for providing additional support. The authors want to thank James Aswegan, John Bieniek, John Hourdakis, Rich Lau, , and Frank Lilja for their assistance. The opinions and errors remain those of the authors.

\section{References}

Bates, J., Dix, M., May, A.D., 1987. Travel time variability and its effect on time of day choice for the journey to work. In: Transportation Planning Methods, Proceedings of Seminar C of PTRC, pp. 299-311.

Black, I.G., Towriss, J.G., 1993. Demand effects of travel time reliability. Center for Logistics and Transportation, Cranfield Institute of Technology.

Bogenberger, K., May, A.D., 1999. Advanced coordinated traffic responsive ramp metering strategies. California PATH working Paper, UCB-ITS-PWP-99-19.

Cambridge Systematics, 2001. MnDOT ramp metering study - Final report. $<$ http://www.dot.state.mn.us/rampmeterstudy/ $>$ Assessed on October 5, 2004.

Gini, C., 1936. On the measure of concentration with espacial reference to income and wealth. Cowles Commission.

Glasser, G.J., 1962. Variance formulas for the mean difference and coefficient of concentration. J. Amer. Stat. Assoc. 57, 648-654.

Haj-Salem, H., Papageorgiou, M., 1995. Ramp metering impact on urban corridor traffic: field results. Transportation Research 29A (4), 303-319.

Hourdakis, J., Michalopoulos, P., 2002. Evaluation of ramp control effectiveness in two Twin Cities freeways. Transportation Research Record. Journal of the Transportation Research Board 1811, 21-29.

Kwon, E., Nanduri, S.V., Lau, R., Aswegan, J., 2001. Comparative analysis of operational algorithms for coordinated ramp metering. Presented at the 2001 Transportation Research Board Conference in Washington, DC, January.

Lawson, T.W., Lovell, D.J., Daganzo, C.F., 1997. Using the input-output diagram to determine the spatial and temporal extents of a queue upstream of a bottleneck. Transportation Research Record 1572, 140-147.

Levinson, D., 2002a. Perspectives on efficiency in transportation. Presented at 2002 Transportation Research Board Conference in Washington, DC, January.

Levinson, D., 2002b. Identifying winners and losers in transportation. Transportation Research Record. Journal of the Transportation Research Board 1812, 179-185.

Levinson, D., Kumar, A., 1994. Operational evidence of changing travel patterns: a case study. ITE Journal (April), 36-44.

Levinson, D., Kumar, A., 1995. A multimodal trip distribution model: structure and application. Transportation Research Record 1466, $124-131$

Levinson, D., Kumar, A., 1997. Density and the journey to work. Growth and Change 28 (2), 147-172.

Lorenz, M.O., 1905. Methods of measuring the concentration of wealth. Publication of the American Statistical Association 9, $209-219$.

Lovell, D.J., Windover, J.R., 1999. Analyzing freeway traffic under congestion: traffic dynamics approach - Discussion by D.J. Lovell and J.R. Windover. ASCE Journal of Transportation Engineering (July/August), 373-375.

Minnesota Department of Transportation (MnDOT), 1996. Traffic management program overview: Twin Cities metro area. Report TMC07043-0196, February 1996.

MnDOT Traffic Management Center, 1998. Ramp metering by zone - The Minnesota algorithm. Working Report.

MnDOT, 2002. http://www.dot.state.mn.us/rampmeterstudy/faqs1010.html\#19.

Newell, G.F., 1982. Application of Queuing Theory, second ed. Chapman and Hall.

Papageorgiou, M., Hadi-Salem, H., Blosseville, J.M., 1991. ALINEA: a local feedback control law for on-ramp metering. Transportation Research Record 1320, 58-64.

Pisarski, A., 1992. New Perspectives in Commuting. US Department of Transportation, Washington, DC.

Ries, G., 1980. Impact of weather on freeway capacity. Mn/DOT Metro Division, Traffic Management Center research project report (unpublished).

Small, K.A., Noland, R.B., Koskenoja, P., 1995. Socio-economic Attributes and impacts of travel reliability: a stated preference approach. PATH Report, MOU-117.

Small, K.A., Noland, R.B., Chu, X., Lewis, D., 1999. Variation of travel-time savings and predictability in congested conditions for highway user-cost estimation. NCHRP Report 431.

Star Tribune, 1999. State senator Dick Day offers 'Freedom to Drive' agenda, October 18, 1999.

Taylor, C., Meldrum, D., 2000. Evaluation of a fuzzy logic ramp metering algorithm: a comparative study among three ramp metering algorithms used in the greater Seattle area. WSDOT Technical Report WA-RD 481.2.

Wascoe, Jr., D., 2000. Do ramp meters encourage urban sprawl? Star Tribune, October 22, 2000.

Weibull, J.W., 1980. On the numerical measurement of accessibility. Environment and Planning A 12, 53-67.

Zhang, L., Levinson, D., 2004. Optimal freeway ramp control without origin-destination information. Transportation Research Part B 38 (10), 869-887.

Zhang, L., Levinson, D., 2005. Balancing efficiency and equity of ramp meters. ASCE Journal of Transportation Engineering 131 (6), 477481. 